Available online at GSC Online Press Directory

GSC Biological and Pharmaceutical Sciences

e-ISSN: 2581-3250, CODEN (USA): GBPSC2

(RESEARCH ARTICLE)

\title{
Citric acid production by Aspergillus niger using banana and plantain peels
}

\author{
Ike Christian Chukwuemeka ${ }^{1,}{ }^{*}$, Onwuakor Chijioke Ethel ${ }^{2}$, Akwari Dike Kalu ${ }^{1}$ and Nwokorie Chukwuma \\ Chigozie 3 \\ ${ }^{1}$ Department of Biological Sciences (Microbiology Programme), College of Basic and Applied Sciences, Rhema University, \\ Nigeria, P.M.B. 7021 Aba, Abia State. \\ 2 Department of Microbiology, Michael Okpara University of Agriculture, Umudike, P.M.B. 7267, Umuahia, Abia State, \\ Nigeria. \\ ${ }^{3}$ Department of Microbiology, Abia State University, Uturu, P.M.B 2000 Uturu, Abia State, Nigeria.
}

Publication history: Received on 22 June 2019; revised on 30 July 2019; accepted on 02 August 2019

Article DOI: https://doi.org/10.30574/gscbps.2019.8.2.0111

\begin{abstract}
The production of citric acid by Aspergillus niger using plantain and banana peels were conducted using standard procedures The inoculated substrate was allowed to ferment for 7 days under appropriate temperature and conditions. Physicochemical results of the fermentation process showed that $\mathrm{pH}$ decreased from $6.5 \pm 0.91 / 6.5 \pm 0.54$ to $2.5 \pm 0.66 / 2.4 \pm 0.33$ for both banana and plantain peels respectively. Total titratable acidity (\%), citric acid yield (\%) and biomass content (mg/L) of the fermentation process increased from $0.074 \pm 0.49 / 0.06 \pm 0.81,0.172 \pm 0.77 /$ $0.156 \pm 0.44$, and $64 \pm 0.51 / 61 \pm 0.08$ to $1.28 \pm 0.61 / 1.24 \pm 0.18,1.304 \pm 0.14 / 1.273 \pm 0.32$, and $330 \pm 0.22 / 298 \pm 0.39$ for both banana and plantain peels respectively. Sugar content (\%) and total solid content (\%) for both banana and plantain peels decreased from $7.8 \pm 0.23 / 6.3 \pm 0.41$ and $16.86 \pm 0.66 / 18.32 \pm 0.08$ to $0.6 \pm 0.19 / 0.7 \pm 0.55$ and $9.96 \pm 0.22$ / $9.34 \pm 0.48$ respectively. This work has shown that banana and plantain peels which were considered waste products and could not amount to any reasonable use had eventually served as potential substrates for the production of citric acid by Aspergillus niger and their utilization will facilitate both the large scale production of this commercially valuable organic acid and also aid in cleaning up of our messed environment, thereby reducing environmental pollution and improving on waste recycling.
\end{abstract}

Keywords: Citric acid; Fermentation; Aspergillus niger; Banana peels; Plantain peels

\section{Introduction}

Citric acid is one of the most versatile and important carboxylic acid intermediate of metabolism in most plants and animals. Citric acid is a tri-basic acid and is naturally produced by microorganisms during tricarboxylic acid (TCA) cycle [1]. Due to its innocuous nature, citric acid is extensively used in food preparations, pharmaceuticals and cosmetics. About 70\% citric acid is used in food industry and remaining 30\% in other industries [2]. Citric acid is widely used to impart a pleasant, tart flavour to foods and beverages. Due to their chelating property and powerful sequestering action with various transient metals (iron, copper, nickel, cobalt, chromium and magnesium), citric acid is used for the phytoremediation of heavy metals from the contaminated soils and sediments [3-4].Recently, citric acid is also increasingly utilized as a monomer for the manufacture of biodegradable polymers which are widely used in various medical applications [5-8].

It is accepted worldwide as a GRAS (generally recognized as safe), as approved by the Joint FAO/WHO Expert Committee on Food Additives [9]. Due to its numerous applications, the volume of citric acid production by

\footnotetext{
${ }^{*}$ Corresponding author

E-mail address: christian_ike@rhemauniversity.edu.ng
}

Copyright (C) 2019 Author(s) retain the copyright of this article. This article is published under the terms of the Creative Commons Attribution Liscense 4.0 
Ike et al. / GSC Biological and Pharmaceutical Sciences 2019, 08(02), 015-021

fermentation is continually increasing at a high annual rate of 5\% [10-11] and also witnessing steadily increasing demand/ consumption. The ever-increasing demand for citric acid mandates the use of both alternative substrate (inexpensive raw materials, such as agro-industrial wastes) and fermentation processes through solid state fermentation. Recently, solid state fermentation (SSF) is considered as an alternative to submerged fermentation in the production of microbial metabolites because of higher yields, low water requirement and lower operating costs [9].

A number of microorganisms have been evaluated for the production of citric acid including bacteria and fungi. These include bacteria: Arthrobacter paraffinens, Bacillus licheniformis, and Corynebacterium species, molds: Aspergillus niger, A. aculeatus, A. carbonarius, A. awamori, A. foetidus, A. fonsecaeus, A. phoenicis and Penicillium janthinellum; and yeasts: Candida tropicalis, C. oleophila, C. guilliermondii, C. citroformans, and Yarrowia lipolytica have been employed for citric acid [12-13]. Most of them are not able to produce commercially acceptable yields due to the fact that citric acid is a metabolite of energy metabolism and its accumulation rises in appreciable amounts only under conditions of drastic imbalances. However, fungal strains of Aspergillus niger remained the organism of choice for citric acid production due to ease of handling, its ability to ferment a variety of cheap raw materials, and high yields [14]. A cost reduction in citric acid production can be achieved by using cheap agricultural wastes such as apple and grape pomace, orange peel, kiwifruit peel, cotton waste, okara soy-residue and cane molasses.

Currently, the global production of citric acid is carried out by fermentation of sucrose or molasses as substrates [9]; [15]. Citric acid is produced by fermentation using inexpensive raw material including crude natural products, such as hydrolysate starch, sugar cane broth and by-products like sugar cane and beet molasses [16]. Molasses is preferably used as the source of sugar for microbial production of citric acid due to its relatively low cost and high sugar (4055\%) content [9]; [15]. Aspergillus niger had the capacity to accumulate significant amounts of citric acid in sugar based medium. However, better successes were achieved using microbial fermentations, and this technique has become the method of ultimate choice for its commercial production, due to economic advantage of biological production over chemical synthesis [17]. With the increase in consumption demand, there is need for substrate alternatives in the manufacture of citric acid that is cheaper and available than the present substrate, especially those of our waste products such as banana and plantain peels that litter the streets and poses disposal problem in the society. This will ensure cleaning up of the environment as part of waste management practices. Therefore, this study assesses the effectiveness of production of citric acid by Aspergillus niger using banana and plantain peels.

\section{Material and methods}

\subsection{Sample collection}

Banana and plantain peels were collected, washed to ensure dirt free and oven-dried at $60^{\circ} \mathrm{C}$ for 2 hours and ground into $2 \mathrm{~mm}$ mesh size.

\subsection{Production of citric acid}

The basal medium was prepared by using ground banana or plantain powder $(60 \mathrm{~g})$ each into different $250 \mathrm{~mL}$ Erlenmeyer flasks. The medium was supplemented in each flask with equal amounts of $0.3 \%$ nitrogen (ammonium nitrate) and phosphorus (ammonium phosphate) supplements and moistened to $60 \%$ moisture content. The flask was cotton plugged and autoclaved at $121^{\circ} \mathrm{C}$ for 15 minutes. The medium was cooled at room temperature; each prepared medium was inoculated with Aspergillus niger $\left(6.0 \times 10^{6} \mathrm{CFU} / \mathrm{mL}\right)$ suspension and incubated at $27{ }^{\circ} \mathrm{C}$ in a rotary shaking incubator for 7 days. $3 \% \mathrm{v} / \mathrm{v}$ methanol was added to the flasks before fermentation. After the fermentation period, the medium was diluted with distilled water $(1: 4 \mathrm{w} / \mathrm{v})$. Then, the medium was filtered and the filtrate was used for the analyses. All samples were prepared in replicates.

\subsection{Assay of physicochemical parameters}

The physicochemical parameters of the fermented substrates of banana and plantain peels using Aspergillus niger to produce citric acid were analyzed using standard methods of AOAC (2007), to determine baseline characteristics and attributes which include $\mathrm{pH}$, total titratable acidity (TTA), sugar content citric acid, total solids, and biomass determinations. Analyses were conducted daily for seven (7) days starting from day 1 and results were recorded accordingly until experiment was concluded on the $7^{\text {th }}$ day. 


\subsection{Statistical analysis}

Analysis of variance (ANOVA) was employed and used to analyze all data obtained. Results are expressed as mean \pm SD (standard deviation).

\section{Results}

Figure 1 showed $\mathrm{pH}$ changes of banana and plantain peels during the fermentation process. During the fermentation process of banana peel, the $\mathrm{pH}$ reduced from $6.5 \pm 0.91$ in day 1 to $2.5 \pm 0.66$ in day 7 ; while during plantain peel fermentation, the $\mathrm{pH}$ also reduced from $6.5 \pm 0.54$ in day 1 to $2.4 \pm 0.33$ in day 7 . The result of $\mathrm{pH}$ reduction obtained for each substrate when compared with fermentation time was statistically significant $(\mathrm{p}<0.05)$.

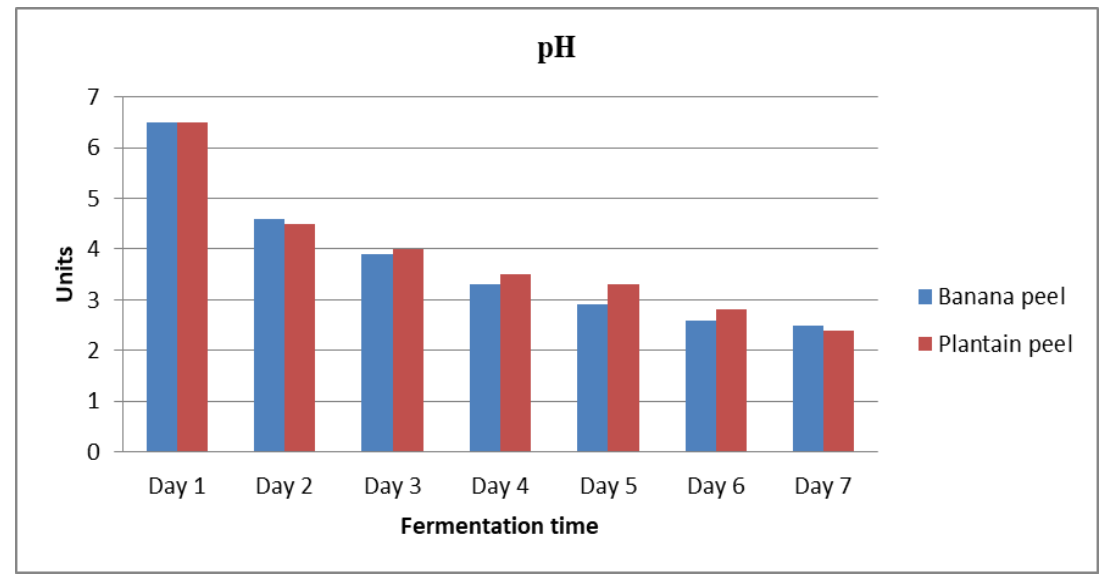

Figure $1 \mathrm{pH}$ changes of banana and plantain peels during the fermentation process

Figure 2 showed total titratable acidity (TTA) percentage of banana and plantain peels during the fermentation process. Total titratable acidity (\%) increased from $0.074 \pm 0.49$ in day 1 to $1.28 \pm 0.61$ in day 7 during banana peel fermentation, while that of plantain peel increased from $0.06 \pm 0.81$ in day 1 to $1.24 \pm 0.18$ in day 7. The result of TTA increase obtained for each substrate when compared with fermentation time was statistically significant $(\mathrm{p}<0.05)$.

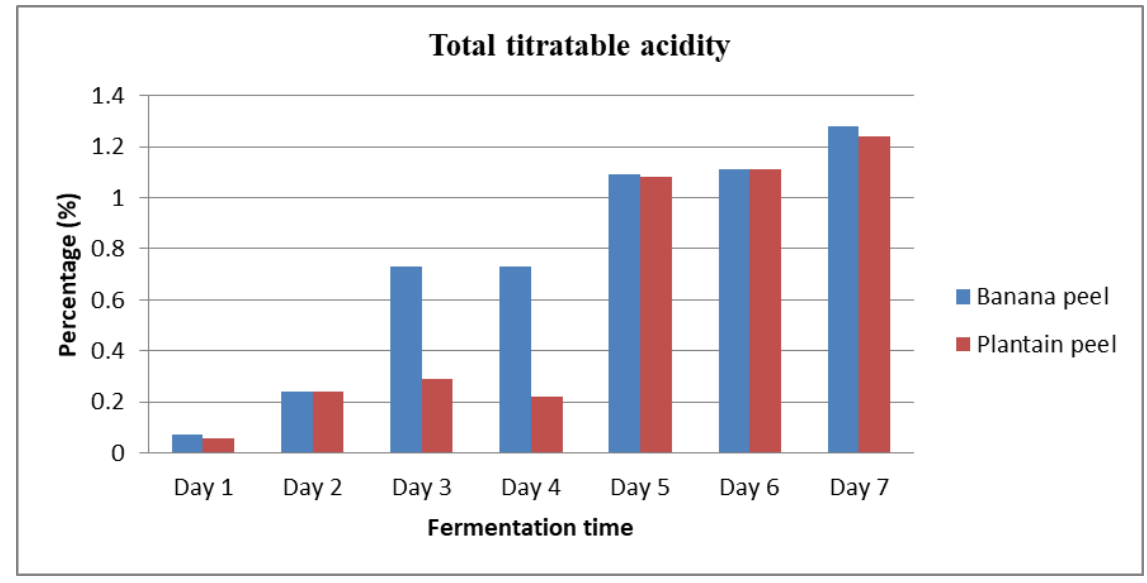

Figure 2 Total titratable acidity (\%) of banana and plantain peels during the fermentation process

Figure 3 showed sugar content (\%) of banana and plantain peels during the fermentation process. Sugar content (\%) of banana peel reduced from $7.8 \pm 0.23$ in day 1 to $0.06 \pm 0.19$ in day 7 during fermentation, while that of plantain peel reduced from $6.3 \pm 0.41$ in day 1 to $0.7 \pm 0.55$ in day 7 . Result of sugar reduction obtained for each substrate during the fermentation process when compared with fermentation time was statistically significant $(p<0.05)$. 


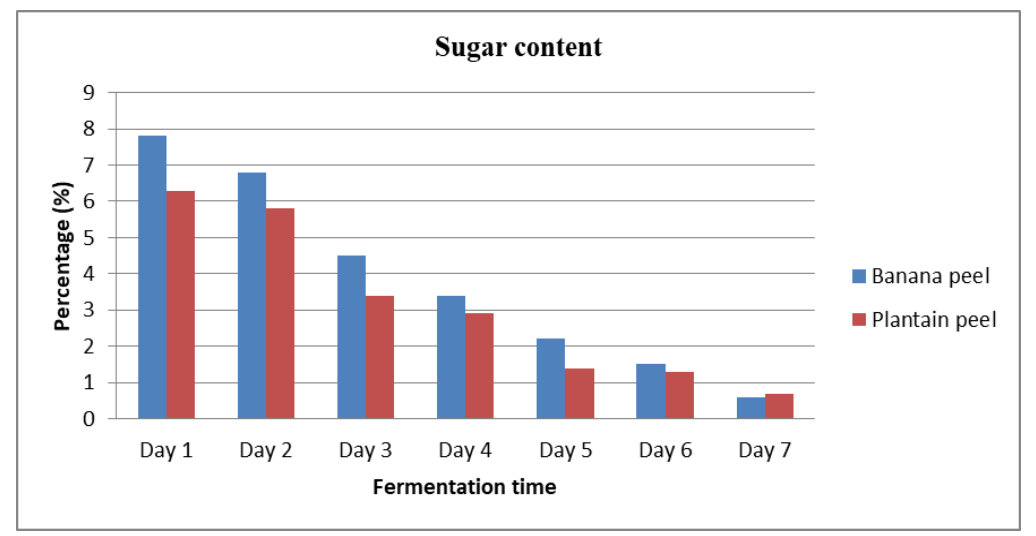

Figure 3 Sugar content (\%) of banana and plantain peels during the fermentation process

Figure 4 showed citric acid content (\%) of banana and plantain peels during the fermentation process. Citric acid (\%) increased from $0.172 \pm 0.77$ in day 1 to $1.304 \pm 0.14$ in day 7 ; while that of plantain peel increased from $0.156 \pm 0.44$ in day 1 to $1.273 \pm 0.32$ in day 7 . The result of citric acid increase obtained for each substrate when compared with fermentation time was statistically significant $(p<0.05)$.

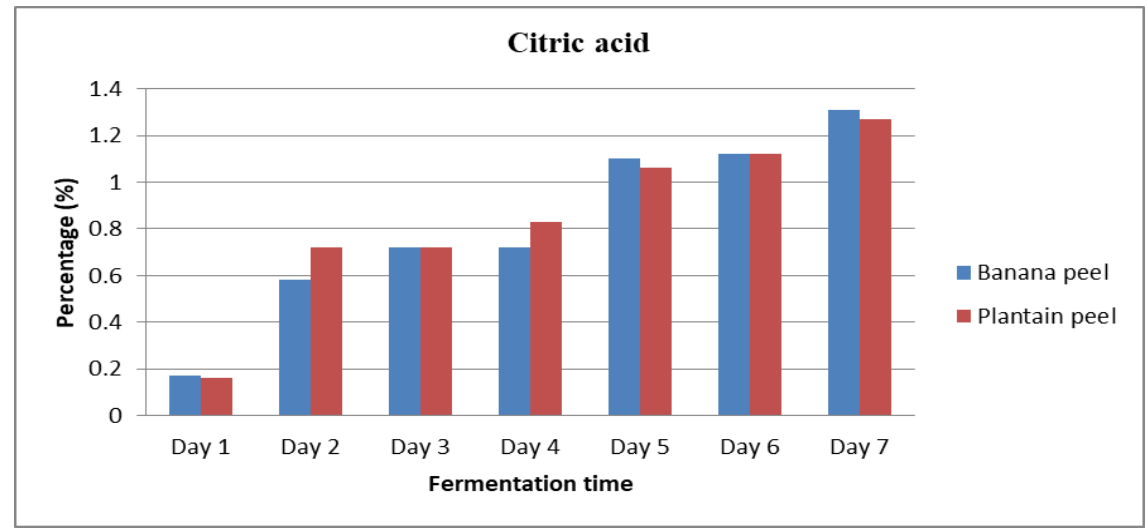

Figure 4 Citric acid content (\%) of banana and plantain peels during the fermentation process

Figure 5 showed total solid percentage (TS \%) of banana and plantain peels during the fermentation process. Total solid (\%) decreased from $16.86 \pm 0.66$ in day 1 to $9.96 \pm 0.22$ in day 7 during banana fermentation, while during plantain fermentation TS decreased from $18.32 \pm 0.08$ in day 1 to $9.34 \pm 0.48$ in day 7 . The decrease in total solid for each substrate when compared with fermentation time was statistically significant $(\mathrm{p}<0.05)$.

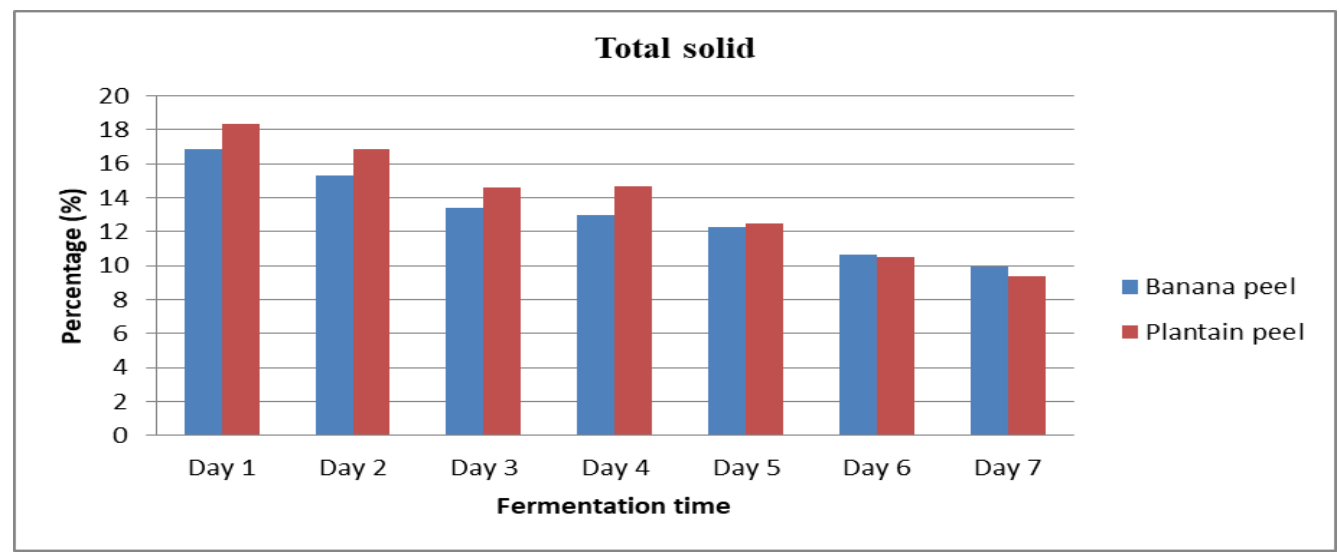

Figure 5 Total solid (\%) of banana and plantain peels during the fermentation process 
Figure 6 showed biomass content of banana and plantain peels during the fermentation process. Biomass content $(\mathrm{mg} / \mathrm{L})$ increased from $64 \pm 0.51$ in day 1 to $330 \pm 0.22$ in day 7 during banana fermentation; while during plantain fermentation it increased from $61 \pm 0.08$ in day 1 to $298 \pm 0.39$ in day 7 . The increase in biomass for each substrate when compared with fermentation time was statistically significant $(\mathrm{p}<0.05)$.

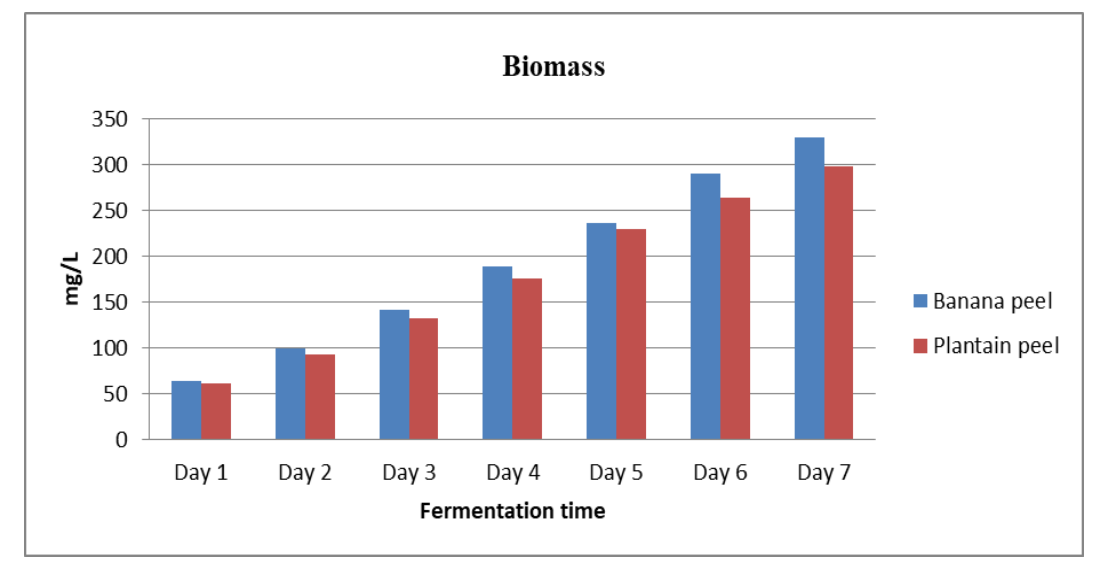

Figure 6 Biomass content (mg/L) of banana and plantain peels during the fermentation process

\section{Discussion}

The citric acid produced from banana and plantain peels showed some physical changes as indicated in the results (Figures 1-6). The value of $\mathrm{pH}$ decreased from $6.5 \pm 0.91$ in day 1 to $2.5 \pm 0.66$ in day 7 for banana peel fermentation, while that of plantain fermentation decreased from $6.5 \pm 0.54$ in day 1 to $2.4 \pm 0.33$ in day 7 . The initial pH shift near neutrality at the beginning of fermentation was important for biomass formation. The progressive decrease in $\mathrm{pH}$ as fermentation time increase was due to the production and accumulation of citric acid through metabolic activities. This assertion was in agreement with the works of [1]; [19]; [20]; [21]. The change in (\%) of total titratable acidity (TTA) of the fermentation process showed an increase of $0.074 \pm 0.49$ to $1.28 \pm 0.61$ and $0.06 \pm 0.81$ to $1.24 \pm 0.18$ from day 1 to day 7 for both banana and plantain peels respectively. This progressive increase in TTA is an indication of presence of malo-latic fermentation. Therefore, there is a clear correlation between total titratable acidity and fermentation time. Thus, as fermentation time increases, total titratable acidity increases. The results obtained in this study correlates with the findings of [20]; [21]. Sugar content (\%) decreased for both banana and plantain peels fermentation from day 1 to day 7 at $7.8 \pm 0.23$ to $0.6 \pm 0.19 / 6.3 \pm 0.41$ to $0.7 \pm 0.55$ respectively. This showed that the fermenting organism (Aspergillus niger) was utilizing the substrates converting them to citric acid through metabolic processes [22]. High citric acid content (\%) was obtained as there was an increase of $0.172 \pm 0.77$ to $1.304 \pm 0.14$ / $0.156 \pm 0.44$ to $1.273 \pm 0.32$ for both banana and plantain peels fermentation respectively from day 1 to day 7 . From the result obtained, there is a direct correlation between sugar utilization, citric acid production, total titratable acidity and fermentation time [19]; [20]. As sugar content decreases, total titratable acidity, citric acid yield and biomass increases with fermentation time. The increase in biomass indicated that fermenting microorganism (Aspergillus niger) were actually replicating. The utilization of substrate nutrients eventually transformed into decreased values that were obtained in this study for total solid (\%) at $16.86 \pm 0.66$ to $9.96 \pm 0.22 / 18.32 \pm 0.08$ to $9.34 \pm 0.48$ for both banana and plantain peels fermentation from day 1 to day 7 [20]. The fermentation substrate (banana and plantain peels) for citric acid biosynthesis were to contain the necessary growth factors, primarily the carbon, nitrogen and phosphorus sources. The overall assessment from the data obtained presented banana peels with better citric acid and biomass yield than plantain peels.

\section{Conclusion}

This work has shown that banana and plantain peel are potential substrates for the production of citric acid by Aspergillus niger and their utilization will facilitate both the large scale production of this commercially valuable organic acid and also aid in cleaning up of our messed environment, thereby reducing environmental pollution and improving on waste recycling. 


\section{Compliance with ethical standards}

\section{Acknowledgments}

The authors are grateful to everyone who contributed in achieving this feat.

\section{Disclosure of conflict of interest}

No conflict of interest.

\section{References}

[1] Okafor N. (2007). Modern Industrial Microbiology and Biotechnology. Science Publisher, New Hampshire 03748, United States of America. 365-379.

[2] Dhillon GS, Brar SK, Verma M and Tyagi RD. (2010). Recent advances in citric acid bio-production and recovery, Food Bioprocess. Technology, 4, 505-529.

[3] Barrington S, Kim JS, Wang L and Kim JW. (2009) Optimization of citric acid production by Aspergillus niger NRRL 567 grown in a column bioreactor, Korean Journal of Chemical Engineering, 26, 422-427.

[4] Chen YX, Lin Q, Luo YM, He YF, Zhen SJ, Yu YL, Tian GM and Wong MH. (2003). The role of citric acid on the phytoremediation of heavy metal contaminated soils, Chemosphere, 50, 807-811.

[5] Naeini AT, Adeli M and Vossoughi M. (2010). Poly (citric acid)-block-poly (ethylene glycol)Copolymers - new candidates for nanomedicine, Nanomedicine.

[6] Djordjevic I, Choudhury NR, Dutta NK and Kumar S. (2009). Synthesis and character-ization of novel citric acidbased polyester elastomers. Polymer, 50, 1682-1691.

[7] Namazi H and Adeli H. (2005). Dendrimers of citric acid and poly (ethylene glycol) as the new drug-delivery agents, Biomaterials, 26, 1175-1183.

[8] Yang J, Webb AR and Ameer GA. (2004). Novel citric acid-based biodegradable elastomers for tissue engineering. Advanced Materials, 16, 511-516.

[9] Soccol CR, Vandenberghe LPS, Rodrigues C and Pandey A. (2006). New Perspectives for Citric Acid Production and Application. Food Technology \& Biotechnology, 44 (2), 141-149.

[10] Finogenova TV, Morgunov IG, Kamzolova SV and Chernyavskaya OG. (2005). Organic acid production by the yeast Yarrowia lipolytica: A review of prospects. Applied Biochemistry and Microbiology, 41, 418-425.

[11] Francielo V, Patricia M and Fernanda SA. (2008). Apple pomace: A versatile substrate for biotechnological applications. Critical Reviews in Biotechnology, 28, 1-12.

[12] Papagianni M. (2007). "Advances in citric acid fermentation by Aspergillus niger: Biochemical aspects, membrane transport and modeling", Biotechnology Advances, 25, 244-263.

[13] Kamzolova SV, Morgunov IG, Aurich A, Perevoznikoa OA, Shishkanova NV, Stottmeister and Finogenova TV. (2005).Lipase secretion and citric acid production in Yarrowia lipolyticayeast grown on animal and vegetable fat. Food Technology \& Biotechnology, 2 (43), 113-122.

[14] Schuster E, Dunn-Coleman N, Frisvad JC and Van Dijek PW. (2002). On the safety of Aspergillus niger - A review. Applied Microbiology and Biotechnology, 59 (4-5), 426-435.

[15] Grewal HS and Kalra KL. (1995). Fungal production of citric acid. Biotechnology Advances, 13, $209-234$.

[16] Yokoya F. (1992). Citric Acid Production. In: Industrial Fermentation Series, Campinas, SP, Brazil. 1-82.

[17] Mattey M. (1992). The production of organic acids. Critical Revised Biotechnology, 12, 87-132.

[18] AOAC. (2007). Official methods of analysis. (18 th ed.) Association of Official AnalyticalChemists; Washington, DC.

[19] Kareem SO and Rahman RA. (2011). Utilization of banana peels for citric acid production by Aspergillus niger. Agriculture and Biology Journal of North America, 4(4), 384-387. 
[20] Kareem SO, Akpan I and Alebiowu 00. (2010). Production of citric acid by Aspergillus niger using pineapple waste. Malaysian Journal of Microbiology, 6(2), 161-165.

[21] Aravantinos-Zafiris G, Tzia C, Oreopoulou V and Thomopoulos CD. (1994). Fermentation of Orange Processing Wastes for Citric Acid Production. Journal of Science, Food \& Agriculture, 65, 117- 120.

[22] Naaz A, Wardah S, Sakhawat A, Shahnaz C and Sana I. (2016). Citric Acid Production from Aspergillus niger using Banana Peel. International Journal of Scientific \& Engineering Research, 7(1), 1580-1583.

\section{How to cite this article}

Ike CC, Onwuakor CE, Akwari DK and Nwokorie CC. (2019). Citric acid production by Aspergillus niger using banana and plantain peels. GSC Biological and Pharmaceutical Sciences, 8(2), 15-21. 